\title{
Watch and Wait - Actualities in the Treatment of Chronic Lymphocytic Leukemia
}

\author{
Szilárd Bíró1, István Benedek Jr¹,2, Árpád Bzduch¹, Johanna Sándor-Kéri1,2, Erzsébet Lázár1,2, \\ István Benedek ${ }^{1,2}$
}

${ }^{1}$ Clinic of Hematology and Bone Marrow Transplantation Unit, Tîrgu Mureș, Romania

2 University of Medicine and Pharmacy, Tîrgu Mureș, Romania

\section{CORRESPONDENCE}

István Benedek Jr

Str. Revoluției nr. 35

540042 Tîrgu Mureș, Romania

Tel: +40 265218739

E-mail: benedekistvan73@yahoo.com

\section{ARTICLE HISTORY}

Received: November 11, 2017

Accepted: December 4, 2017
Szilárd Bíró • Str. Revoluției nr. 35, 540042 Tîrgu Mureș, Romania. Tel: +40 265218739 Árpád Bzduch • Str. Revoluției nr. 35, 540042 Tîrgu Mureș, Romania. Tel: +40 265218739 Johanna Sándor-Kéri • Str. Revolutiei nr. 35, 540042 Tîrgu Mureș, Romania. Tel: +40 265218739 Erzsébet Lázár • Str. Revolutiei nr. 35, 540042 Tîrgu Mureș, Romania. Tel: +40 265218739

István Benedek • Str. Revolutiei nr. 35, 540042 Tîrgu Mureș, Romania. Tel: +40 265218739

\begin{abstract}
In Western countries, chronic lymphocytic leukemia (CLL) is one of the most diagnosed leukemia types among elderly patients. CLL is described as an indolent lymphoproliferative disorder, characterized by the presence of a high number of small, mature B-cells in the peripheral blood smear, with a particular immunophenotype (CD5, CD19, CD23 positive and CD20 dim positive) and accumulation in the bone marrow and lymphoid tissue (e.g., lymph nodes, spleen). The experience of the past decades showed that CLL is clinically very heterogeneous; while some patients present a chronic clinical evolution, with a prolonged survival, in which the treatment can be delayed, others suffer from a more aggressive form, which must be treated early and is associated with many relapses. This observation led to several genomic studies that have mapped the genetic modifications involved in the disease conformations, including del(13q14), del(11q), or trisomy 12. On the other hand, certain genetic mutations such as del(17p13)-p53, NOTCH1 mutation, or ZAP70/CD38 increased expression are associated with worse clinical outcome. In order to apply the right treatment strategy, the RAI and BINET staging systems should be considered, which are based on clinical and laboratory assessment, on genetic mutations that may influence the resistance to chemotherapy, as well as the patient's age and comorbidities. The aim of this manuscript was to present the therapeutic approaches of CLL, in order to attempt to answer the following question: to treat, or not to treat? This clinical update focuses on the managements of CLL patients in the 21 st century.
\end{abstract}

Keywords: chronic lymphocytic leukemia, treatment, stem cell transplantation, conservatory therapy

\section{INTRODUCTION}

Chronic lymphocytic leukemia (CLL) is a frequent form of leukemic malignancy among adults in developed countries. The incidence was reported around 4 to 6 cases per 100,000 persons per year in Europe and in the United States. The incidence increases with age, most of the patients being diagnosed after the age of 65. A lower incidence of CLL is maintained in Asian individuals, however. 
TABLE 1. The RAl staging system

\begin{tabular}{|c|c|c|}
\hline Stage & Characteristics & Median survival \\
\hline 0 & $\begin{array}{l}\text { lymphocytosis }\left(>5 \times 10^{9} \mathrm{~B} \text { lymphocytes } / \mathrm{L}\right) \text { in the blood and } \\
\text { bone marrow aspirate, with atypical lymphocytes }\end{array}$ & $>150$ months \\
\hline । & stage $0+$ lymphadenopathies & 101 months \\
\hline$\|$ & $\begin{array}{l}\text { stage } 0+\text { splenomegaly and/or hepatomegaly associated with } \\
\text { or without lymphadenopathies }\end{array}$ & 71 months \\
\hline III & anemia, with serum hemoglobin level <11 g/dL & 19 months \\
\hline IV & thrombocytopenia, platelet count $<100,000 / \mathrm{mm}^{3}$ & 19 months \\
\hline
\end{tabular}

TABLE 2. The BINET staging system (lymphoid areas include the laterocervical, axillary, inguinal lymph nodes, liver, and spleen)

\begin{tabular}{ll}
\hline Stage & Characteristics \\
\hline A & lymphocytosis $\left(>5 \times 10^{9}\right.$ B lymphocytes/L) and 2 lymphoid areas affected \\
B & lymphocytosis $\left(>5 \times 10^{9} \mathrm{~B}\right.$ lymphocytes/L) and 3 or more lymphoid area affected \\
C & anemia $(H b<10 \mathrm{~g} / \mathrm{dL})$ and $/$ or thrombocytopenia $\left(\mathrm{Plt}<100,000 / \mathrm{mm}^{3}\right)$ independent of the \\
& number of lymphoid area affected \\
\hline
\end{tabular}

TABLE 3. Chronic Lymphocytic Leukemia-International prognostic Index (CLL-IPI)

\begin{tabular}{lll}
\hline Category & Overall survival (at $\mathbf{5}$ years ) & Clinical approach \\
\hline Low risk & $93.2 \%$ & „Watch and wait” \\
Intermediate risk & $79.3 \%$ & Treat in case of symptoms \\
High risk & $63.3 \%$ & $\begin{array}{l}\text { Treatment indication, only if the disease } \\
\text { is active (symptomatic) }\end{array}$ \\
Very high risk & $23.3 \%$ & $\begin{array}{l}\text { If it is possible, treat with novel agent or } \\
\text { enroll in clinical trials }\end{array}$ \\
\hline
\end{tabular}

Despite affecting older age subjects, in the last years, CLL was found more frequently in younger individuals, less than 55 years of age. Based on the gender distribution, males get sick more often compared to women (male : female ratio $1.5-2: 1){ }^{1,2} \mathrm{CLL}$ is a chronic lymphoproliferative disease, accounting for one third of adult leukemia cases and one quarter of non-Hodgkin lymphomas (NHL). ${ }^{3}$ According to the WHO classification (World Health Organization, 2008), CLL is an indolent lymphoproliferative disorder, composed by small, mature, monomorphic, monoclonal B-cells accumulating in peripheral blood, bone marrow, and lymphoid organs. ${ }^{4}$ The monoclonal character of these cells is based on the particular immunophenotype that includes specific cellular surface markers (CD5 - T-cell antigen; CD19, CD23, and CD20 as B-cell antigens). On the other hand, the WHO states that the difference between CLL and small lymphocytic lymphoma (SLL) is only in the leukemic appearance. ${ }^{5}$

\section{DIAGNOSIS OF CLL}

The positive diagnosis of CLL is based on blood smears, full blood cell count, and immunophenotyping from peripheral blood. 5

According to the International Workshop on Chronic Lymphocytic Leukemia (IWCLL), ${ }^{6,7}$ updated by the National Cancer Institute-Working Group (NCI-WG) guidelines, ${ }^{7,8}$ CLL diagnosis is based on the presence of documented lymphocytosis ( $\geq 5 \times 10^{9} \mathrm{~B}$ lymphocytes/L) in the peripheral blood in the last 3 months; and secondly, flow cytometry showing a specific immunophenotypic outline: CD5 and CD23 expression with a low-level expression of $\mathrm{CD} 20, \mathrm{CD} 79 \mathrm{~b}$, and surface immunoglobulin, as well as clonal light chain restriction (either kappa or lambda).

During the analysis of the peripheral blood smear, the leukemia cells present as healthy, mature, small lymphocytes with little cytoplasm and a dense nucleus with aggregated chromatin, without recognizable nucleoli. .5 


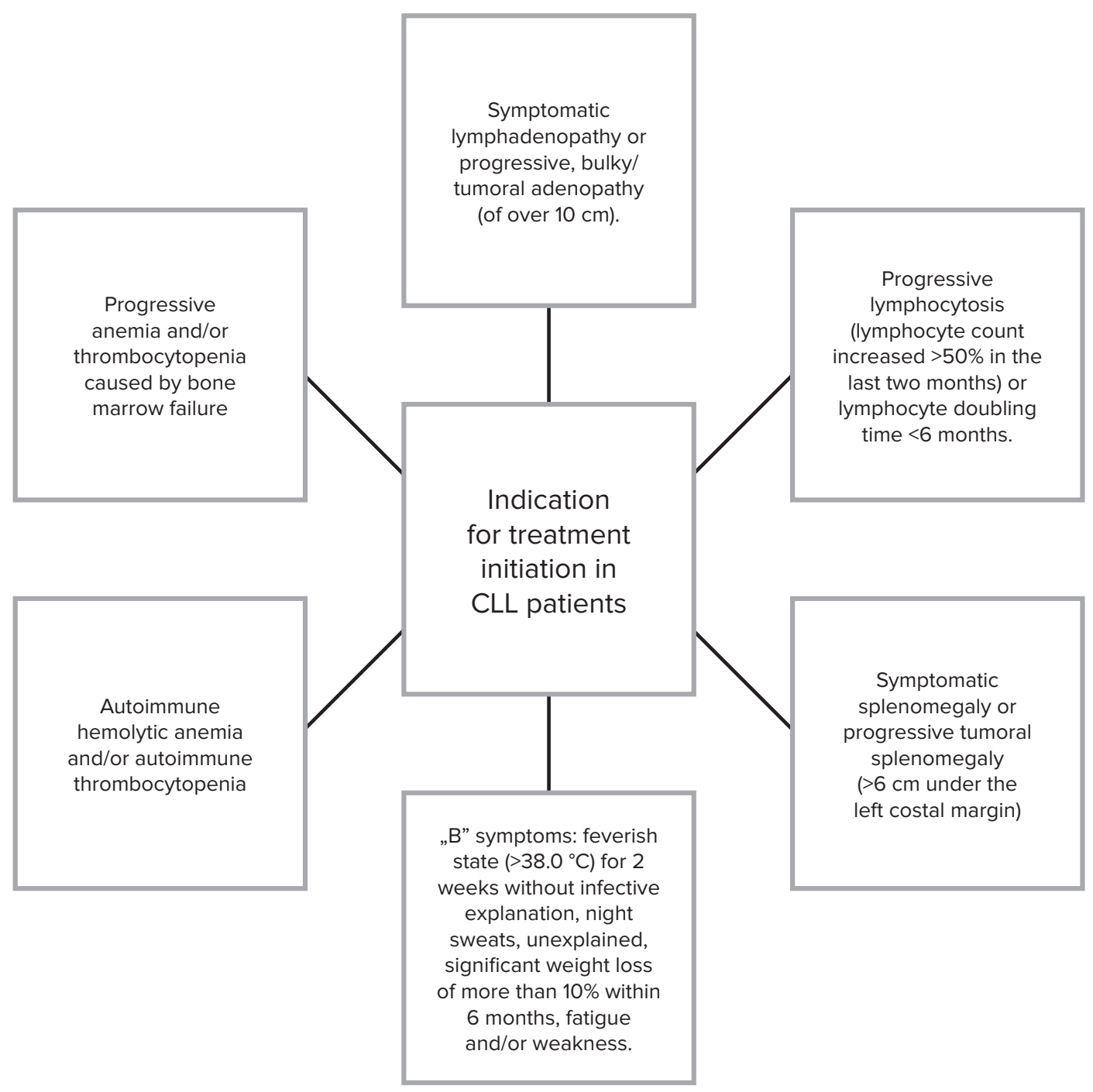

FIGURE 1. Indications for treatment in CLL according to the International Workshop on Chronic Lymphocytic Leukemia Guidelines

Hallek et al. and Scarfo et al. mention two clinical entities: small lymphocytic lymphoma and monoclonal B-cell lymphocytosis, which must be distinguished from CLL by assessing the signs and symptoms and the count of $\mathrm{B}$ lymphocytes in the peripheral blood. The diagnosis of lymphocytic lymphoma involves the presence of less than $5 \times 10^{9} \mathrm{~B}$ lymphocytes/ $\mathrm{L}$ in the peripheral blood and is clinically characterized by lymphadenopathies and/or enlarged spleen and liver, without bone marrow infiltrationrelated cytopenia, requiring, in some cases, histopathologic examination from a lymph node. Monoclonal B-cell lymphocytosis is confirmed by a B-lymphocytes blood count under $5 \times 10^{9} / \mathrm{L}$, in the absence of lymphadenopathies, hepatosplenomegaly, disorder-related cytopenia, or B symptoms. 5,7

\section{STAGING AND RISK STRATIFICATION OF CLL}

In current clinical practice, the RAI and BINET staging systems are available for defining disease prognosis and indication for treatment in CLL patients. ${ }^{9}, 10$

The RAI staging system includes 4 stages that present the median survival according to the laboratory and clinical features of the disease, and it allows classification of patients into three risk categories (Table 1). Low-risk patients present RAI stage 0 , intermediate risk includes stages I and II, while high-risk patients include stages III and IV, with anemia and/or thrombocytopenia. ${ }^{9}$

The BINET staging system categorized patients into 3 classes, according to the B-lymphocyte count and the number of affected lymphoid regions, and the hemoglobin and platelet count (Table 2). ${ }^{10}$ 
The disadvantage of the two staging systems is that they allow the identification of only three prognostic subgroups. However, in the last two decades, genetic studies have isolated several genomic and chromosomal modifications in patients with CLL that present prognostic value irrespective of the clinical stage. In consequence, an international consortium of study groups has developed a relevant prognostic score - the Chronic Lymphocytic Leukemia-International Prognostic Index (CLL-IPI). In this staging system, five independent prognostic factor were included: age, clinical stage, serum 32 -microglobulin levels, IGHV mutational status, and $\operatorname{del}(17 \mathrm{p})$ and/or TP53 mutation. $.7,11$

\section{THERAPEUTIC GUIDELINES - INDICATION FOR TREATMENT}

The two main questions to be answered before commencing a proper patient management in CLL are "When?" and "How?". ${ }^{2}$ The International Workshop on Chronic Lymphocytic Leukemia clearly defined the signs and/or symptoms of active disease that has indication for prompt treatment initiation (Figure 1).6,7,11

\section{PROPER SELECTION OF TREATMENT REGIMENS}

When faced with a diagnosis of CLL, the clinician should assess the proper timing and method, either in monotherapy or with combination drug regimens, for initiating the therapeutic management of such patients. Therefore, several parameters should be evaluated, which include (1) the fitness of the patient (age, comorbidity, performance status, comorbidity index of rating scale - CIRS, renal function); (2) the stage of the disease (RAI and BINET); (3) disorder-related symptoms; (4) gene mutations [del (17p) and or TP53 mutation]; (5) previous treatment, as well as the presence of relapse or refractory disease to the last administered treatment regimens. $.7,11$

Considering the 5 parameters previously listed, there are different possible treatment modalities.

\section{The "Watch and wait" conduct}

Delayed treatment initiation can be applied in case of CLL patients with RAI stage 0 to I and BINET stage A and B, irrespective of the gene mutations and fitness.

\section{First-line therapy}

In fit patients ("go go"), with normal organ and kidney function, with a creatinine clearance of $>70 \mathrm{~mL} /$ minute, with a CIRS of $\leq 6$, the current procedure is to apply standard combination chemotherapy with fludarabine, cyclophosphamide and CD20 monoclonal antibody - rituximab (FCR). Two comprehensive studies have shown an outstanding response rate with this scheme, with an overall response rate of $90 \%$ and a rate of complete response of $40 \% .^{12,13}$ But the toxicity of this combination may lead to a greater incidence of grade 3 or 4 neutropenia and bacterial or viral infections within the first 2 years after treatment. ${ }^{14,15}$ Unfortunately, there is no suitable data on methods for toxicity reduction and the only way is to reduce the treatment cycles during minimal residual disease (MRD). ${ }^{16}$ An alternative treatment may be the combination of bendamustine + rituximab (BR). ${ }^{16}$ At the same time, a randomized GCLLSG trial (2013) showed that the BR combination presents a better clinical tolerance, but the clinical remission rate and progression-free survival were shown to be inferior to that of the FCR combination. ${ }^{18}$

In unfit patients, ("slow go"), with damaged organ functions (creatinine clearance less than $70 \mathrm{~mL} /$ minute) and several relevant comorbidities (CIRS score $>6$ ), the therapeutic method of choice is the chlorambucil (alkylating agent) and anti-CD20 antibody combination. In 2014, Goede et al., used the chlorambucil + obinutuzumab (antiCD20 antibody) scheme and were able to prove a higher clinical response rate compared to chlorambucil monotherapy and a longer progression-free survival; however, the authors did not study the side effect profile of this regimen. ${ }^{19}$ In 2013, Hillmen et al. reported similar results with the use of chlorambucil and ofatumumab combination. ${ }^{20}$ According to Foon et al. (2009), the FCR-lite regimen consists in reducing the doses of fludarabine, cyclophosphamide and rituximab down to the patient's tolerability. ${ }^{21}$

High-risk patients, with del(17p) and/or TP53 mutations present a negative, reserved prognosis, but the recommendations are not clear about the standard therapy, which underlines the importance of patient enrollment in clinical experiments with novel drugs.

Currently, new kinase inhibitors (ibrutinib and idelalisib) are approved by the Food and Drug Administration and the European Medicines Agency as the main treatment line in patients with $17 \mathrm{p}$ deletion and/or TP53 mutation. ${ }^{5,7}$

Ibrutinib is an inhibitor of Bruton-tirosine kinase, linked irreversibly to B-cell receptor, which acts on this pathway by inducing apoptosis and blocking the proliferation process. Its adverse effects include coagulopathies (manifested with bleeding), gastrointestinal effects (e.g., diarrhea), and also CYP3A4 interactions, thus indicating careful administration in association with other inducers 
of inhibitors of cytochrome p450. Also, it had also been proven useful in relapsed/refractory CLL. ${ }^{22-24}$

Idelalisib is a phosphoinositide 3-kinase (PI3K) inhibitor, with oral administration, and as side effects it causes hepatic cytolysis, lung involvement, and colitis with diarrhea. ${ }^{25,26}$ This drug presents first-line indication in patients with del(17p), and, on the other hand, it can be associated with anti-CD20 monoclonal antibody (rituximab) for relapsed or refractory CLL. ${ }^{27}$

\section{Second-line therapies (for relapsed and refractory CLL)}

This category of patients is a gray zone too. But the recommendations are the same for patients who have received a first-option immunochemotherapy combination (such as FCR) and they relapse after more than 24 to 36 months. ${ }^{12}$ On the other hand, if the relapse occurs within 24-36 months after the end of the treatment, or the subjects are refractory to the fludarabine-based combination (with non-progressive or progressive disease or patients who relapse within 6 months after the end of treatment), the option of clinical trial enrollment should be taken into account. In such cases, there are several possibilities of treatment. The use of alemtuzumab and fludarabine combination has been shown by Elter et al. (2011) to reach a response rate of more than $80 \%$ and a clinical remission in $30 \%$ of cases. ${ }^{28}$ The anti-CD20 monoclonal antibody in association with corticosteroids were proposed by Castro et al. (2008), by administering rituximab in days 1,8 , and 15 , with high doses of methylprednisolone $\left(1 \mathrm{~g} / \mathrm{m}^{2}\right)$ over a 4-week period. ${ }^{29}$ Ibrutinib and idelalisib (without or with rituximab) have also been proved as indication in this patient category, ${ }^{23,27}$ ofatumumab is a second-generation anti-CD20 monoclonal antibody that binds to a different epitope of the CD20 surface marker. It shows a tardive dissociation, which leads to a better, more efficient complement-dependent cytotoxicity. This effect is superior compared to rituximab. In double-refractory (resistant to fludarabine + alemtuzumab) CLL patients, ofatumumab is a suggested treatment possibility. ${ }^{30}$

\section{Allogeneic stem cell transplantation}

Sutton et al., Montserrat et al., and Magni et al. have shown that autologous stem cell transplantation dose not present a superior, significant effect on the general survival rates and on the progression-free survival, in comparison to standard immunochemotherapy schemes (e.g., fludarabine, cyclophosphamide, and rituximab regimen). ${ }^{31-33}$
In young CLL patients with refractory disease, with or without genetic abnormalities (17p deletion and/or TP53 mutation), allogeneic stem cell transplantation should be taken into consideration. ${ }^{34}$ This statement is encouraged by the fact that although new pharmacological agents (tyrosine-kinase inhibitors and new-generation monoclonal antibodies) have reformed the treatment modalities in CLL, there has yet to be sufficient information on their long-term efficacy and safety. As a final thought, in these patients, after the right novel agent has been chosen and has led to an optimal response, there are two options for furthering the treatment. The first option consists in performing allogeneic stem cell transplantation in order to conserve the clinical response, and the second option is to delay the cell therapy and to continue the initiated treatment with the novel drug.

\section{OUTLOOK ON THE FUTURE OF CLL TREATMENT}

Over the last two decades, there have been multiple developments that triggered a change in the therapeutic management of CLL. Due to several genetic investigations, clinicians are mapping the genetic background, which has led to a better understanding of why this indolent lymphoproliferative disease presents a slow progression in some patients (with a longer period of inactivity of the disease), while other patients should be treated shortly after diagnosis, by initiating proper therapeutic measures.

\section{CONCLUSIONS}

Comprehensive clinical studies have generated new personalized guidelines, which indicate "when" and "how" to treat patients with chronic lymphocytic leukemia. Novel pharmacological agents have significantly improved clinical outcomes in high-risk, relapsed, or refractory CLL. At the same time, there are still unanswered questions regarding the safety and long-term efficacy of such novel therapies, which require further clinical studies that may be able to provide clear answers.

\section{CONFLICT OF INTEREST}

Nothing to declare.

\section{REFERENCES}

1. SEER Cancer Statistics Review (CSR), 1975-2011. Available at: seer.cancer. gov/csr/1975_2011/

2. Scarfò L, Ferreri AJM, Ghia P. Chronic Iymphocytic leukaemia. Crit Rev Oncol Hematol. 2016;104:169-182. 
3. Hallek M, Pflug N. Chronic lymphocytic leukemia. Annals of Oncology. 2010;21:vii154-viii64.

4. Hallek M. Chronic lymphocytic leukemia: 2015 Update on diagnosis, risk stratification, and treatment. Am J Hematol. 2015;90:446-460.

5. Hallek M. Chronic lymphocytic leukemia: 2017 update on diagnosis, risk stratification, and treatment. Am J Hematol. 2017:92:946-965.

6. Hallek M, Cheson BD, Catovsky D, et al. Guidelines for the diagnosis and treatment of chronic lymphocytic leukemia: a report from the International Workshop on Chronic Lymphocytic Leukemia updating the National Cancer Institute-Working Group 1996 guidelines. Blood. 2008;111:5446 5456.

7. Scarfò L, Ferreri AJM, Ghia P. Chronic lymphocytic leukaemia. Crit Rev Oncol Hematol. 2016;104:169-182.

8. Cheson BD, Bennett JM, Grever M, et al. National Cancer Institutesponsored Working Group guidelines for chronic lymphocytic leukemia: revised guidelines for diagnosis and treatment. Blood. 1996;87:49904997.

9. Rai KR, Sawitsky A, Cronkite EP, Chanana AD, Levy RN, Pasternack BS. Clinical staging of chronic lymphocytic leukemia. Blood. 1975;46:219-234

10. Binet JL, Auquier A, Dighiero G, et al. A new prognostic classification of chronic lymphocytic leukemia derived from a multivariate survival analysis. Cancer. 1981;48:198-206.

11. Riwa S, Marcel M. Chronic Lymphocytic Leukemia (CLL): Upfront Treatment Options in 2017. Hematol Transfus Int J. 2017;4:00076.

12. Ghia P, Hallek M. Management of chronic Iymphocytic leukemia. Haematologica. 2014;99:965-972.

13. Keating MJ, O'Brien S, Albitar $\mathrm{M}$, et al. Early results of a chemoimmunotherapy regimen of fludarabine, cyclophosphamide, and rituximab as initial therapy for chronic lymphocytic leukemia. J Clin Oncol. 2005;23:4079-4088.

14. Hallek M, Fischer K, Fingerle-Rowson G, et al. Addition of rituximab to fludarabine and cyclophosphamide in patients with chronic lymphocytic leukaemia: a randomised, open-label, phase 3 trial. Lancet. 2010;376:1164 1174

15. Tam CS, O'Brien S, Wierda W, et al. Long-term results of the fludarabine: cyclophosphamide, and rituximab regimen as initial therapy of chronic lymphocytic leukemia. Blood. 2008;112:975-980.

16. Strati P, Keating MJ, O'Brien SM, Burger J, et al. Eradication of bone marrow minimal residual disease may prompt early treatment discontinuation in CLL. Blood. 2014;123:3727-3732.

17. Fischer $\mathrm{K}$, Cramer $\mathrm{P}$, Busch $\mathrm{R}$, et al. Bendamustine in combination with rituximab for previously untreated patients with chronic lymphocytic leukemia: a multicenter phase II trial of the German Chronic Lymphocytic Leukemia Study Group. J Clin Oncol. 2012;30:3209-3216.

18. Eichhorst $B$, Fink $A M$, Busch $R$, et al. Chemoimmunotherapy with Fludarabine (F), Cyclophosphamide (C), and Rituximab (R) (FCR) versus Bendamustine and Rituximab (BR) in previously untreated and physically fit patients (pts) with advanced chronic lymphocytic leukemia (CLL): results of a planned interim analysis of the CLL10 Trial, an international, randomized study of the german CLL Study Group (GCLLSG). Blood. 2013;122:Suppl.21:abstract 526
19. Goede $\mathrm{V}$, Fischer $\mathrm{K}$, Busch R, et al. Obinutuzumab plus chlorambucil in patients with CLL and coexisting conditions. N Engl J Med. 2014;370:11011110.

20. Hillmen $P$, Robak $T$, Janssens A, et al. Ofatumumab + Chlorambucil versus chlorambucil alone in patients with untreated chronic lymphocytic leukemia (CLL): results of the phase III study complement 1 (OMB110911). Blood. 2013;122:Suppl21:abstract 528.

21. Foon KA, Boyiadzis M, Land SR, et al. Chemoimmunotherapy with lowdose fludarabine and cyclophosphamide and high dose rituximab in previously untreated patients with chronic lymphocytic leukemia. J Clin Oncol. 2009;27:498-503.

22. O'Brien S, Furman RR, Coutre SE, et al. Ibrutinib as initial therapy for elderly patients with chronic lymphocytic leukaemia or small lymphocytic lymphoma: an open-label, multicentre, phase1b/2 trial. Lancet Oncol. 2014;15:48-58.

23. Byrd JC, O'Brien S, James DF. Ibrutinib in relapsed chronic Iymphocytic leukemia. N Engl J Med. 2013:369:1278-1279.

24. Brown JR, O'Brien S, Barrientos JC, et al. Ibrutinib versus ofatumumab in previously treated chronic lymphoid leukemia. N Engl J Med. 2014;371:213223

25. Brown JR, Byrd JC, Coutre SE, et al. Idelalisib: an inhibitor of phosphatidylinositol 3-kinase p110delta,for relapsed/refractory chronic lymphocytic leukemia. Blood. 2014;123:3390-3397.

26. Flinn IW, Kahl BS, Leonard JP, et al. Idelalisib: a selective inhibitor of phosphatidylinositol 3-kinase-delta, as therapy for previously treated indolent non-Hodgkin Iymphoma. Blood. 2014;123:3406-3413.

27. Furman RR, Sharman JP, Coutre SE, et al. Idelalisib and rituximab in relapsed chronic lymphocytic leukemia. N Engl J Med. 2014;370:997-1007.

28. Elter T, Gercheva-Kyuchukova L, Pylylpenko H, et al. Fludarabine plus alemtuzumab versus fludarabine alone in patients with previously treated chronic lymphocytic leukaemia: a randomised phase 3 trial. Lancet Oncol. 2011;12:1204-1213

29. Castro JE, Sandoval-Sus JD, Bole J, Rassenti L, Kipps TJ. Rituximab in combination with high-dose methylprednisolone for the treatment of fludarabine refractory high-risk chronic lymphocytic leukemia. Leukemia. 2008;22:2048-2053

30. Wierda WG, Kipps TJ, Mayer J, et al. Ofatumumab as single-agent CD20 immunotherapy in fludarabine-refractory chronic lymphocytic leukemia. $J$ Clin Oncol. 2010;28:1749-1755.

31. Montserrat E, Gribben JG. Autografting CLL: the game is over. Blood. 2011:117:6057-6058.

32. Sutton L, Chevret S, Tournilhac O, et al. Autologous stem cell transplantation as first-line treatment strategy for chronic Iymphocytic leukemia: a multicentre, randomized, controlled trial from the SFGM-TC and GFLLC. Blood. 2011;117:6109-6119.

33. Magni M, Di Nicola M, Patti $\mathrm{C}$, et al. Results of a randomized trial comparing high-dose chemotherapy plus Auto-SCT and R-FC in CLL at diagnosis. Bone Marrow Transplant. 2014;49:485-491.

34. Dreger P, Schetelig J, Andersen N, et al. Managing high risk CLL during transition to a new treatment era: stem cell transplantation or nove agents? Blood. 2014;124:3841-3849. 